\title{
A coastal storms intensity scale for the Catalan sea (NW Mediterranean)
}

\author{
E. T. Mendoza ${ }^{1, *}$, J. A. Jimenez ${ }^{1}$, and J. Mateo $^{2}$ \\ ${ }^{1}$ Laboratori d'Enginyeria Marítima, Universitat Politècnica de Catalunya, Barcelona, Spain \\ ${ }^{2}$ Servei Meteorològic de Catalunya, Barcelona, Spain \\ *now at: Laboratorio de Ingenieria y Procesos Costeros, Ins. Ing., Sisal, Yucatan, Mexico
}

Received: 20 June 2010 - Revised: 10 February 2011 - Accepted: 28 June 2011 - Published: 15 September 2011

\begin{abstract}
A 5-class intensity scale for wave storms in the Catalan coast is presented. This has been done by analysing a storm data set which comprises 5 buoys during the period 1988/2008. The obtained classification improves the former proposal of Mendoza and Jiménez (2008) by better resolving spatial and temporal variability in wave storms in the area. The obtained classification reflects the increase in wave storm properties as the storm category increases. Because the selected classification parameter was the energy content which implicitly contains $H_{\mathrm{S}}$ and storm duration, this variable was used to define class limits; class I storms $\left(24-250 \mathrm{~m}^{2} \mathrm{~h}\right)$, class II storms $\left(251-500 \mathrm{~m}^{2} \mathrm{~h}\right)$, class III $\left(501-700 \mathrm{~m}^{2} \mathrm{~h}\right)$, class IV storms $\left(701-1200 \mathrm{~m}^{2} \mathrm{~h}\right)$ and class V storms $\left(>1200 \mathrm{~m}^{2} \mathrm{~h}\right)$. The energy content variable was also used as proxy for induced hazards; the observed increase in energy content for higher classes reflected a significant increase in the intensity of the potential hazards. Lastly, the dominant synoptic situation for wave storms along the Catalan coast was the presence of a Mediterranean cyclone although a direct correspondence on cyclone's intensity over the western Mediterranean with wave energy content was not found.
\end{abstract}

\section{Introduction}

A storm can be defined in a simple manner as a violent atmospheric perturbation accompanied by strong winds, among other elements. When this happens in the sea, the most immediate effects are the increase in wave height and sometimes sea level (storm surge). These events drive a series of morphodynamic responses such as beach and dune erosion,

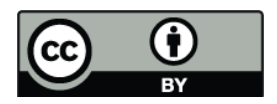

Correspondence to: J .A. Jimenez (jose.jimenez@upc.edu) overwash and inundation of low-lying areas that have important consequences upon the coastal geomorphology. The magnitude of these processes and responses is proportional to the storm energy content and, in this sense: high-energy storms can significantly accelerate existing rates of shoreline erosion (Morton and Sallenger, 2003).

The practical consequences of these processes include great damage to existing infrastructure, disturbance of coastal ecosystem services, and a negative effect on coastal use in general. The importance of storm events and their induced hazards is explicit in the Protocol on ICZM in the Mediterranean (PAP/RAC, 2007), signed in 2008 by the EU and the Mediterranean countries. This Protocol includes a specific chapter on Natural Hazards (Chapter 22), in which the parties are advised to undertake vulnerability and hazard assessments of coastal zones and take prevention, mitigation and adaptation measures to address the effects of natural disasters.

One of the simplest approaches with which to estimate the impact of these events is based on the use of an intensity storm scale where each storm is associated to a given class in terms of a variable characterising its hazardous potential. Examples of such approaches are the well-known Saffir-Simpson scale for hurricanes (Simpson, 1971; Saffir, 1977) or the scale proposed by Dolan and Davis (1992) for Atlantic storms.

Following this approach, Mendoza and Jimenez (2008) presented a first storm classification for the NW Mediterranean to be used in a vulnerability assessment framework (Mendoza and Jiménez, 2009). However, the used dataset was limited to one location in the South of the Catalan coast and, although representative for storm conditions in that area, it does not necessarily represent the rest of the coast well. To improve that classification and to make it representative of all possible storm conditions, this work is an update in the analysis by including wave storms recorded along the entire

Published by Copernicus Publications on behalf of the European Geosciences Union. 


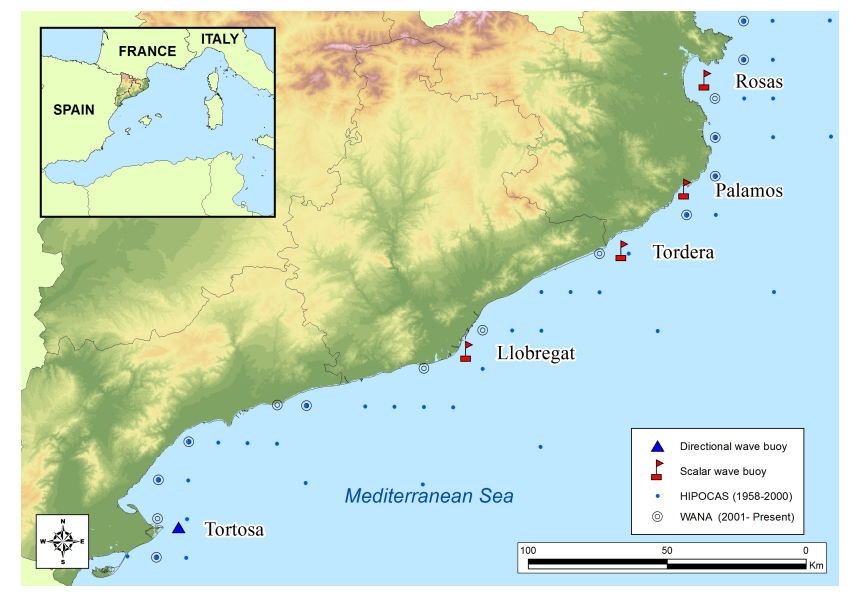

Fig. 1. Study area and location of buoys and wave prediction nodes.

Catalan coast from north to south to cover all possible spatial variations in storm conditions.

Within this context, the main aim of this work is to obtain an intensity scale for wave storms in the Catalan coast (NW Mediterranean) and to identify the main synoptic situations driving such events. This will result in a storm classification where each class will be characterized in terms of wave height, wave period, duration and energy content.

\section{Study area and data}

Catalonia is situated in the NE coast of Spain in the Mediterranean Sea (Fig. 1). It has a coastline about $600 \mathrm{~km}$ long and is characterized by great geodiversity. It can be divided in 7 coastal units (Mendoza, 2008) comprising cliffs and rocky coasts, sandy beaches and wetlands. Approximately $40 \%$ of the coast is formed by sandy beaches of different types and dimensions, from long to pocket beaches.

The Catalan coastal zone concentrates approximately $50 \%$ of the population and it contributes up to $10 \%$ of the Catalan GDP, with tourism being one of the most important economic activities in the area (e.g. Sardá et al., 2005). It concentrates a large number of infrastructures and, at present, about $70 \%$ of the beaches are subjected to erosion processes and more than $50 \%$ of the coastal municipalities have reported some damages in existing infrastructures in beaches (CIIRC, 2009).

The data used in this study to characterize storms are wave records obtained from 5 wave buoys located along the Catalan coast which permit us to cover any spatial variability in wave conditions (see location in Fig. 1). The operating period, type of instrument (omnidirectional-scalar- and directional) and depth of each buoy can be seen in Table 1.
Table 1. Main characteristic of wave buoys (O: omnidirectional (scalar) buoy D: directional buoy).

\begin{tabular}{lclr}
\hline Buoy & Type & Dates & Depth $(\mathrm{m})$ \\
\hline Roses & O & $1992 / 972000 / 08$ & 46 \\
Palamós & O & $1988 / 2008$ & 90 \\
Tordera & O D & $1984 / 972000 / 072007 / 08$ & 74 \\
Llobregat & O D & $1984 / 972000 / 042004 / 08$ & 45 \\
Tortosa & D & $1990 / 2008$ & 60 \\
\hline
\end{tabular}

In the area, there is a larger database built up by 44-yr hindcast wave data (1958-2001) obtained within the HIPOCAS project (Guedes Soares, 2008; Ratsimandresy et al., 2008). Although this database is extremely useful to analyze long-term trends and large spatial patterns, when the interest is to analyze real values at any location during storm conditions, modelled data may differ from real ones (Bolaños et al., 2007; Ponce de León and Guedes Soares, 2008). As an example, Casas-Prat and Sierra (2010) using Hipocas data for the Catalan coast found differences in the wave height up to $1.75 \mathrm{~m}$ for the original data and up to $2.83 \mathrm{~m}$ for the calibrated data set during storm conditions. Due to this and taking into account that the final objective is to derive a classification for coastal storms based on "real" wave characteristics, it was decided to use the recorded values whereas hindcasted values are only used to see the exceptionality of a given storm in the long-term.

The data used to classify synoptic situations of weather conditions over the Catalan coast were fields of sea-level pressure (SLP) and geopotential heights at the $500 \mathrm{hPa}$ level (Z500) during identified storm events. They have been obtained from ERA-Interim reanalysis done by European Centre for Medium Weather Forecast (ECMWF).

\section{Methodology}

To develop a storm classification, three main steps have to be done: (1) storm definition and identification, (2) selection of the parameter to characterize the storms according to a given criteria, and (3) selection and application of a classification method.

In this work, a storm is defined as a wave event in which the significant wave height $\left(H_{\mathrm{s}}\right)$ exceeds a threshold value of $2 \mathrm{~m}$ (this value was also recommended by the Spanish Harbour Authority to perform extreme wave analysis) during a minimum period of $6 \mathrm{~h}$. This combination has been used based on the works of Mendoza and Jiménez (2006), who identified it as the minimum storm conditions required to generate a significant impact in the coast measured in terms of erosion and inundation. Also, an additional criterion was imposed to identify statistically independent storms. Thus, a storm involving two extreme episodes with a maximum 
inter-event separation of $72 \mathrm{~h}$ and a period of $H_{\mathrm{s}}<1.5 \mathrm{~m}$ shorter than $6 \mathrm{~h}$ is considered a single two-peaked storm (Mendoza and Jiménez, 2006). This was done because some cases where the evolution of meteorological conditions result in the presentation of twin peaks storms were detected.

Because one of the main objectives of the classification is to provide an idea about the potential hazards induced by the storms, the classification variable should reflect their intensity. To this end, the storm "energy content", $E$, is used and is given by

$$
E=\int_{t 1}^{t 2} H_{\mathrm{s}}^{2} \mathrm{~d} t
$$

where $t 1$ and $t 2$ define the storm duration $\left(H_{\mathrm{S}}>H_{\mathrm{S}}\right.$ threshold). The use of a single wave height value to characterize the storm (e.g. storm-averaged $H_{\mathrm{s}}$ or $H_{\mathrm{s}}$ at the peak of the storm) might result in an underestimation or overestimation of the actual wave storm energy.

Once storms were identified and characterized by their energy content for all buoy records, they were integrated into a single storm data set. The practical result of this integration is that one meteorological event can be represented in the dataset by different wave values reflecting the spatial variability of the event. This is clearly illustrated in Fig. 2, where wave records at different locations along the Catalan coast during a storm on December 2008 show very different $H_{\mathrm{s}}$ values. With this approach, it was possible to take into account that the same meteorological event is able to produce wave storms of different energy contents along the coast. The objective of this data aggregation is to build up a database comprising all the possible wave characteristics typical of storm conditions at any location along the Catalan coast in such a way that the derived classification should cover the possible range of storm conditions. With obvious differences, the idea behind this aggregation is similar to the technique applied in Regional Frequency Analysis where "space is traded for time", i.e. data from several sites are used to estimate event frequencies at that - spatially integrated site.

Finally, the classification process was carried out by means of cluster analysis, which permits the reduction of the amount of data by categorizing or grouping them in terms of similarity. In this study the average linkage method was used, and although it tends to produce a great number of small groups, it is generally superior to other clustering methods and has been successfully used in climate studies (see Bunkers et al., 1996).

In order to reduce the tendency to produce a large number of groups, a supervised classification was applied to resulting clusters to produce a 5 category classification considering the obtained dendrogram partition, the cluster consistency and the energy content variation within each group. The selection of a 5 categories scale was made to maintain the analogy with existent storm scales (Simpson, 1971; Saffir, 1977; Dolan and Davis, 1992; Mendoza and Jimenez, 2008). The selected

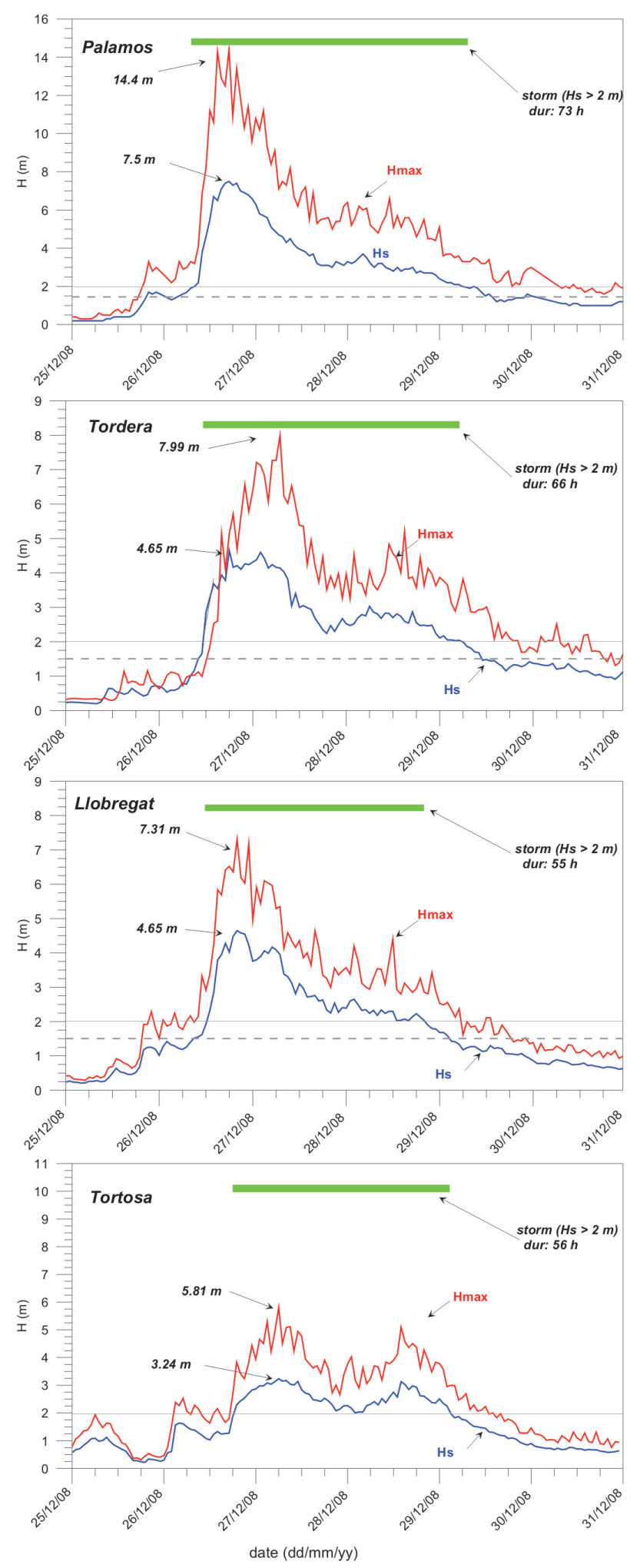

Fig. 2. Spatial variability along the Catalan coast during a storm in December 2008. 


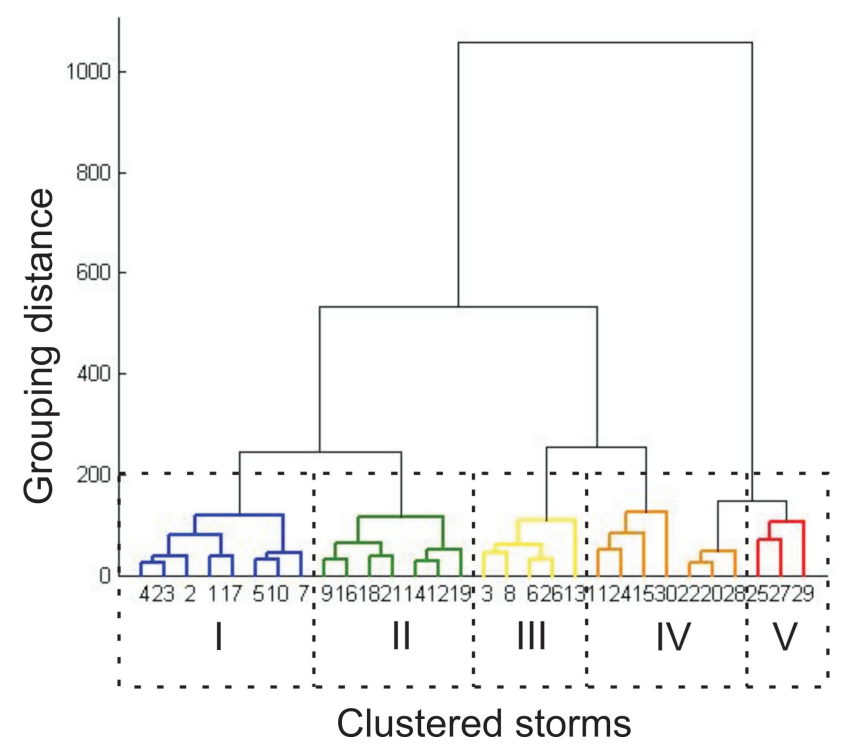

Fig. 3. Storm classification using cluster analysis (solid lines) and supervised classification (dashed lines). Numbers in the $\mathrm{x}$-axis are clusters' identifiers.

scale categorizes the storms into: I - weak, II - moderate, III - significant, IV - severe and V - extreme.

Once recorded storms were classified, the corresponding synoptic situations generating these events were identified. To do this, SLP and Z500 fields recorded every $6 \mathrm{~h}$ during the storm development were analyzed and categorized into three main synoptic situations according to the position of the low and high pressure centres over Spain (see Sect. 4.4).

As an example of potential management applications, the magnitude of the two most common storm-induced hazards in beaches was estimated: beach profile erosion and inundation. The representative value for each class has been calculated by averaging all the values calculated for each individual storm belonging to the corresponding class. In order to cover the variations in hazard intensity due to existing differences in beach characteristics along the Catalan coast, two representative beach profiles have been selected following Mendoza and Jiménez (2009): (i) a reflective profile composed by coarse sand, a high berm and a steep slope, which is representative of areas such as Costa Brava ( $\mathrm{N}$ coast) and Maresme (central coast) and, (ii) a dissipative profile, composed by fine sand, a low berm and very mild slopes which is especially frequent from Barcelona to the south. The erosion hazard has been characterized by estimating the potential volume of sediment eroded from the beach during the impact of the storm. To characterize the inundation potential of a given storm the wave-induced maximum water level at the shoreline was used, i.e. the wave run-up. Inundation is the result of the excess of water level with respect to land elevation and, to evaluate it, the coastal topography should be required. Since this work is only interested in assessing

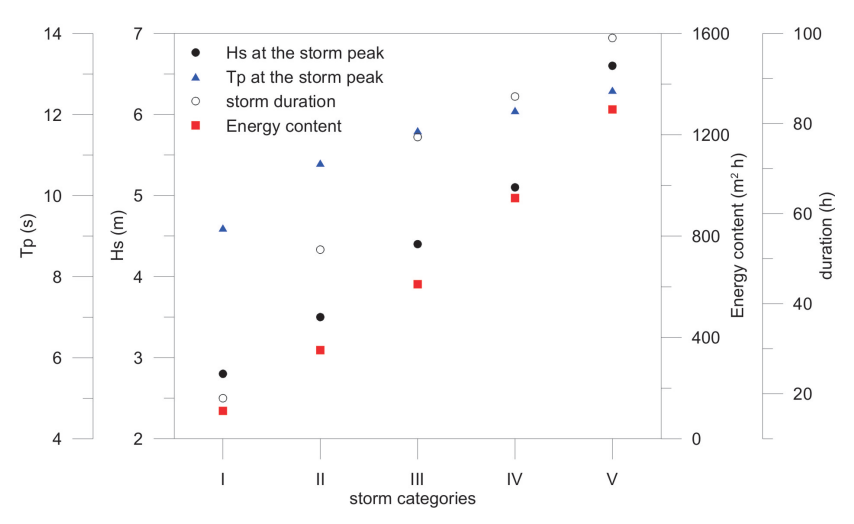

Fig. 4. Class-averaged values of wave storm properties in the Catalan coast.

the contribution of the forcing (storm) to such a process, the induced run-up as a proxy of the inundation potential of the considered storm was used. The erosion volume was calculated using the parametric model proposed by Mendoza and Jiménez (2006) and the run-up was calculated by using the model proposed by Stockdon et al. (2006).

\section{Results}

\subsection{Storm classes}

The application of the selected $H_{\mathrm{S}}$ threshold criteria resulted in a total number of 599 storm records in all the analyzed buoys from 1988 to 2008 . It has to be taken into account that this number does not correspond to the number of meteorological events since, in most of the cases, the same forcing event is recorded as a wave storm in different locations (buoys) with different characteristics (e.g. Fig. 2). These 599 storm records along the coast correspond to 286 meteorological stormy situations that represent an average presentation of 13 events per year during the period 1988/2008.

The application of the clustering analysis is shown in Fig. 3 and the resulting class-averaged values of $H_{\mathrm{s}}, T_{\mathrm{p}}$, duration and energy content for each storm type can be seen in Fig. 4 and Table 2. As it can be observed, the increase in storm category is accompanied by an increase in all wave variables at different rates. One of the consequences of having a classification based on the storm energy content is that to properly classify a given event, it is necessary to take into account the two variables controlling its magnitude (Eq. 1): wave height and duration (Fig. 5).

Figure 4 shows that the wave period is the variable showing the smallest variation with storm category. Thus, although it increases for more intense categories, it only varies an absolute value of $3 \mathrm{~s}$ over the full range. It has to be considered that this is a fetch-limited sea environment, which is characterized by the presence of short period waves with maximum recorded $T_{\mathrm{p}}$ values of about $13 \mathrm{~s}$ (García et al., 
Table 2. Averaged characteristics of storm classes recorded during the period 1988-2008.

\begin{tabular}{ccccr}
\hline $\begin{array}{c}\text { Storm } \\
\text { class }\end{array}$ & $\begin{array}{c}H_{\mathrm{s}} \max \\
(\mathrm{m})\end{array}$ & $\begin{array}{c}T_{\mathrm{p}} \max \\
(\mathrm{s})\end{array}$ & $\begin{array}{c}\text { Duration } \\
(\mathrm{h})\end{array}$ & $\begin{array}{r}\text { Energy } \\
\left(\mathrm{m}^{2} \mathrm{~h}\right)\end{array}$ \\
\hline I & 2.8 & 9.2 & 19 & $110(24-250)$ \\
II & 3.5 & 10.8 & 52 & $350(250-500)$ \\
III & 4.4 & 11.6 & 77 & $610(501-700)$ \\
IV & 5.1 & 12.1 & 86 & $950(701-1200)$ \\
V & 6.6 & 12.6 & 99 & $1300(>1200)$ \\
\hline
\end{tabular}

1993; Jiménez et al., 1997). The wave height at the peak of the storm increases about 2.5 times in the full range of categories whereas the duration increases about 5 times. Finally, the largest increase in magnitude was observed for the energy content in such a way that the $\mathrm{E}$ of category- $\mathrm{V}$ storms is 13 times larger than category-I events. These results indicate that the produced classification clearly reflects the variations in wave storm magnitudes and, in particular, the increase from one category to the upper ones will reflect a significant increase in the storm wave content and, in consequence, in its hazard potential.

In terms of frequency of occurrence, and as expected, the smaller the storm category is, the most frequent the event will be. Thus, from the 599 storm records, $77.8 \%$ fall into class I-weak, $17.03 \%$ are class II-moderate-, $3 \%$ are class III-significant, $1.67 \%$ are class IV-severe and, only the $0.5 \%$ ( 3 cases) belongs to class V-extreme. This can also be expressed in terms of probability of occurrence (or the equivalent return period, $T_{\mathrm{R}}$, obtained after fitting an extreme distribution). Thus, for instance, the estimated return periods of each class at the $\mathrm{S}$ part of the Catalan coast are: (I) $<1 \mathrm{yr}$; (II) $\sim 2 \mathrm{yr}$; (III) $\sim 5 \mathrm{yr}$; (IV) $\sim 10 \mathrm{yr}$; (V) $\sim 50 \mathrm{yr}$. It has to be considered that the probability of occurrence of each storm category varies along the coast. In this sense, the central part of the Catalan coast (Llobregat buoy in Fig. 1) can be classified as the mildest zone in terms of the storms' energetic content in such a way that, it is the area with the smallest number of recorded storms of highest categories (one category-IV event and none of category- $\mathrm{V}$ have been recorded).

\subsection{Direction and seasonality}

Figure 6 shows the direction distribution of wave storms during the analyzed period for each category, where three main components are identified: Eastern (E), Northern (N) and Southern (S). From these, the E sector presented the largest number with $57 \%$ of the total number of storms; in addition the most energetic storms registered (belonging to class IV and $\mathrm{V}$ ) are associated to this directional sector. This result is consistent with previous observations that classified the $\mathrm{E}$ storms as the most energetic in the Catalan coast due to the

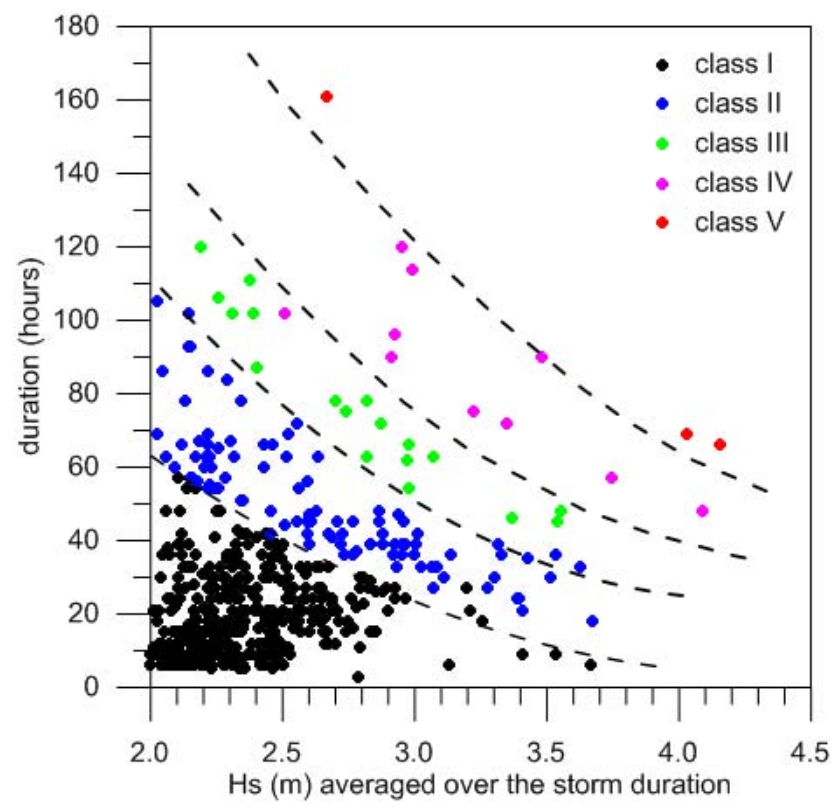

Fig. 5. Storm-averaged $H_{\mathrm{s}}$ and duration for each category for all the recorded events.

associated fetch and wind regime in the area (García et al., 1993; Jiménez et al., 1997).

The second most represented sector is the $\mathrm{N}$, and it corresponds to storms occurring at the northernmost part of the Catalan coast which are produced by locally generated very strong winds, the Tramuntana. Its influence in the central and southern coast is negligible.

The $\mathrm{S}$ storms are the least frequent in the area, with about a $20 \%$ of occurrence. These storms have usually low energy contents, in such a way that they have only been registered as class-I and class-II events. However this does not mean that their effects should be neglected. Thus, their presence along the Catalan coast in periods of absence of E storms can induce important beach rotation processes in embayed beaches (see e.g. Jiménez et al., 2003; Ojeda and Guillén, 2008).

Figure 7 shows the seasonal distribution of storms during the analysed period. This distribution reflects a mean climatic year with two seasons according to the storm regime: The storm season from October to April and the calm season from May to September. The limits of both seasons are defined by months with storm activity (May and September) although normally restricted to low energy events. The storms type I and II are present throughout the year although with higher frequency in the stormy season. The storms that belong to the most energetic classes (III, IV and V) mainly verify from October to January and they are frequently associated to the presence of low pressure systems over the Catalan Sea (Jiménez et al., 1997; Cateura et al., 2004). This is the so-called storm season in the Mediterranean when the 


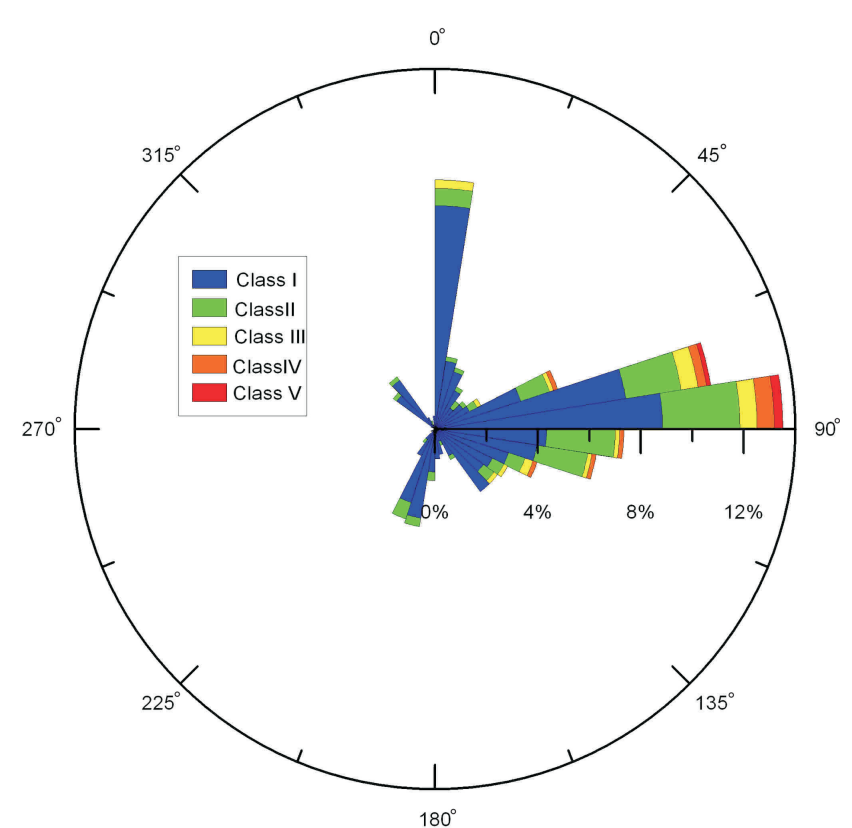

Fig. 6. Directional distribution of storms in the Catalan coast during the period 1988/2008.

most intense period in cyclogenesis over the basin occurs (Lionello et al., 2006).

\subsection{Potential hazards}

Figure 8 shows the estimated class-averaged representative volume loss potential and run-up values for the Catalan coast. As expected, the higher the intensity of the storm, the larger the eroded volume will be. Thus, mean eroded volume values range from about $10 \mathrm{~m}^{3} / \mathrm{m} /$ storm to $100 \mathrm{~m}^{3} / \mathrm{m} / \mathrm{storm}$ for classes I and V, respectively, in reflective beaches and from $7 \mathrm{~m}^{3} / \mathrm{m} /$ storm to $25 \mathrm{~m}^{3} / \mathrm{m} /$ storm for dissipative ones. This means that the increase in the magnitude of the erosion potential due to the increase of storm category mainly affects reflective beaches. It has to be considered that these amounts represent the erosion capacity of the storm and that they will verify only if such volume is available at a given coastal stretch. In other words, they characterize the contribution of the forcing (storm) to the considered hazard (erosion).

In the case of inundation potential, similar results are found. The runup values range from about 1.75 to $3.75 \mathrm{~m}$ for classes I and V, respectively, in reflective beaches and from 0.75 to $1.5 \mathrm{~m}$ for dissipative ones. As expected, the higher the intensity of the storm, the larger the run-up magnitude. Thus, the run-up is doubled from class-I storms to class- $\mathrm{V}$ ones. For the analyzed beaches, the estimated runup for reflective conditions is about two times larger than the one associated to dissipative ones.

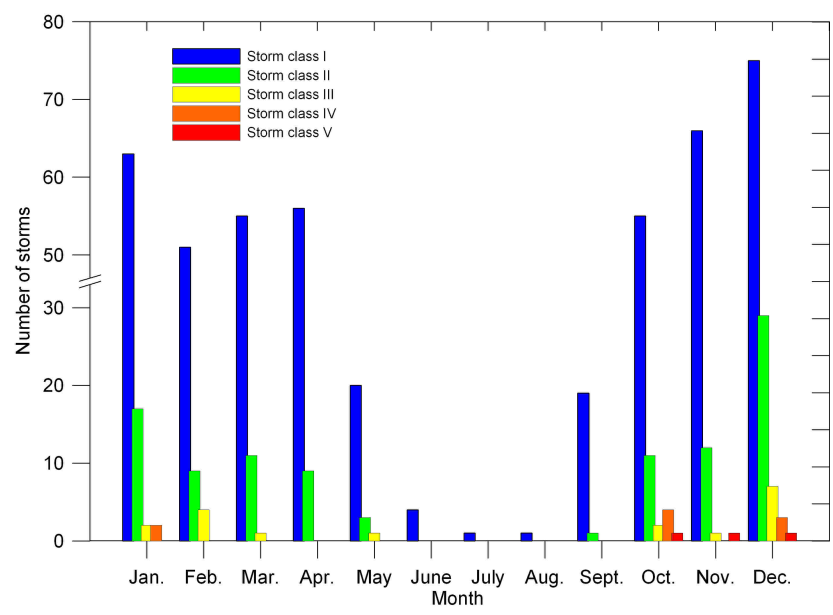

Fig. 7. Seasonal distribution of storms in the Catalan coast during the period 1988/2008.

\subsection{Synoptic situations}

After the analysis of synoptic maps observed during the identified storms, three main synoptic situations were found to dominate over the Catalan Sea. They are:

Mediterranean Cyclone (MC). It is characterized by a low pressure centre over the W Mediterranean (Fig. 9). These storms can present mesoscale features and weak intensity or they can cover a wide area with a strong intensity (e.g. Radinovic, 1987; Campins et al., 2000). As an example of this variability, Fig. 9 shows two different patterns of pressure gradients associated to this situation. Cyclogenesis mechanisms in the Mediterranean have been largely analyzed in the literature (see e.g. Trigo et al., 2002).

South Advection (SA). This situation is characterized by the presence of a low pressure centre over the Atlantic. This centre usually generates large pressure gradients at sea level (Fig. 10). The low pressure area is usually large and the Catalan coast can be affected and be subjected to the action of southern winds of varying main direction (SE, S, SW).

East Advection (EA). This situation is characterized by the presence of a high pressure centre over North or Central Europe and a low-pressure centre over North Africa. It could also be classified as MA-like. This results in eastern winds blowing along the Catalan coast (Fig. 11).

Table 3 shows the synoptic situation associated to the presence of some of the most important recorded storms in the Catalan coast. As it can be seen, MC is the dominant synoptic situation during storms, with the most energetic 

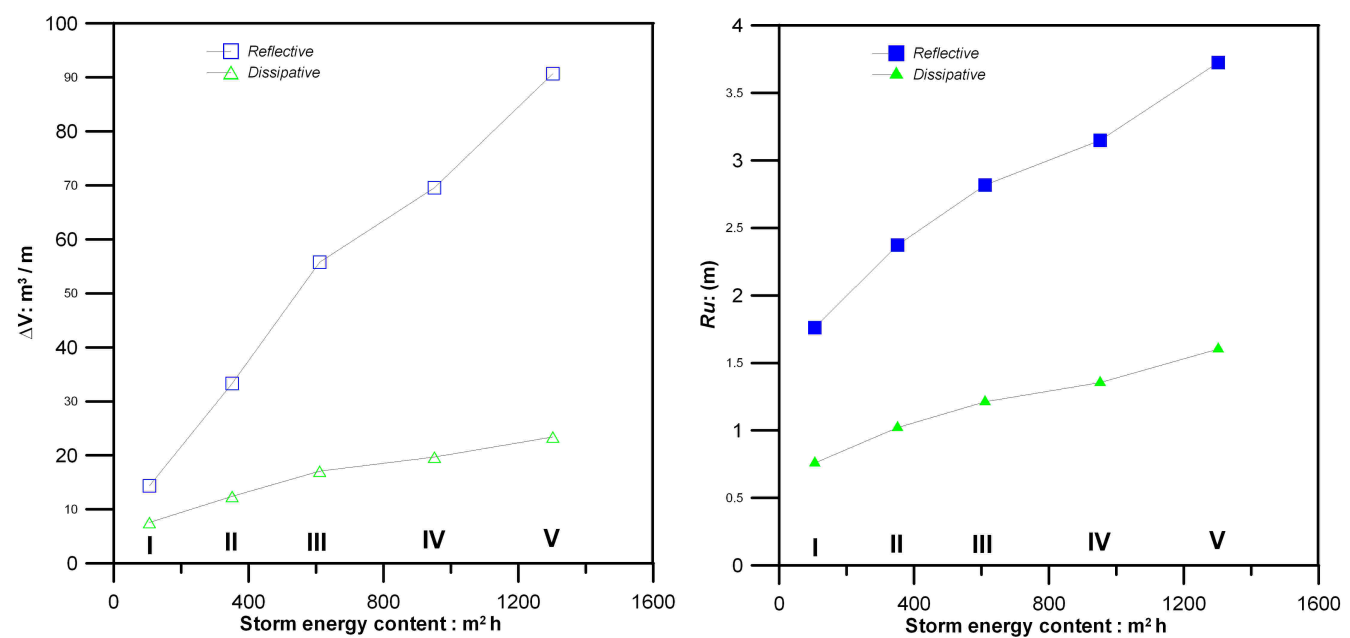

Fig. 8. Magnitude of storm-induced coastal hazards in representative beaches of the Catalan coast (left: beach profile erosion, right: wave run-up).

Table 3. Synoptic situations for the most intense storms identified along the Catalan coast during the period 1984-2008.

\begin{tabular}{llrrrrr}
\hline $\begin{array}{l}\text { start date } \\
(\mathrm{dd} / \mathrm{mm} / \mathrm{yy})\end{array}$ & $\begin{array}{l}\text { end date } \\
(\mathrm{dd} / \mathrm{mm} / \mathrm{yy})\end{array}$ & $\begin{array}{r}\text { duration } \\
\text { (hours })\end{array}$ & $\begin{array}{r}H_{\mathrm{S}} \\
(\mathrm{m})\end{array}$ & $\begin{array}{r}E \\
\left(\mathrm{~m}^{2} \mathrm{~h}\right)\end{array}$ & $\begin{array}{r}\text { storm } \\
\text { category }\end{array}$ & $\begin{array}{r}\text { synoptic } \\
\text { situation }\end{array}$ \\
\hline $09 / 11 / 2001$ & $16 / 11 / 2001$ & 161 & 6.0 & 1370 & $\mathrm{~V}$ & $\mathrm{MC}$ \\
$26 / 12 / 2008$ & $29 / 12 / 2008$ & 69 & 7.5 & 1300 & $\mathrm{~V}$ & $\mathrm{MC}$ \\
$14 / 10 / 2003$ & $19 / 10 / 2003$ & 112 & 6.3 & 1230 & $\mathrm{~V}$ & $\mathrm{MC}$ \\
$29 / 01 / 1996$ & $03 / 02 / 1996$ & 120 & 5.7 & 1150 & IV & SA \\
$16 / 12 / 1997$ & $19 / 12 / 1997$ & 75 & 5.8 & 880 & IV & SA \\
$21 / 12 / 2000$ & $25 / 12 / 2000$ & 90 & 4.5 & 820 & IV & SA \\
$14 / 12 / 2001$ & $17 / 12 / 2001$ & 72 & 6.0 & 700 & IV & MC \\
$25 / 02 / 2003$ & $28 / 02 / 2003$ & 81 & 4.6 & 670 & III & SA \\
$28 / 10 / 1997$ & $30 / 10 / 1997$ & 45 & 5.2 & 660 & III & MC \\
$28 / 03 / 2004$ & $03 / 03 / 2004$ & 159 & 4.6 & 650 & III & SE \\
$17 / 02 / 2003$ & $21 / 02 / 2003$ & 102 & 4.5 & 640 & III & SA \\
$05 / 12 / 2004$ & $10 / 12 / 2004$ & 120 & 3.5 & 620 & III & MC \\
$20 / 12 / 2006$ & $24 / 12 / 2006$ & 106 & 3.0 & 550 & III & SE \\
$03 / 01 / 2008$ & $05 / 01 / 2008$ & 46 & 4.9 & 550 & III & SA \\
$16 / 11 / 1989$ & $19 / 11 / 1989$ & 63 & 3.8 & 540 & III & SA \\
$08 / 10 / 1990$ & $11 / 10 / 1990$ & 75 & 4.5 & 530 & III & MC \\
$06 / 05 / 2002$ & $09 / 05 / 2002$ & 62 & 4.1 & 420 & III & SE \\
$28 / 01 / 2006$ & $31 / 01 / 2006$ & 78 & 4.3 & 410 & III & MC \\
\hline
\end{tabular}

ones (category V) only being developed under this situation. Category-IV storms verify under MC and SA situations whereas EA only produces category-III events.

If we compare the eight most intense storms identified from cyclone's intensity reported by Genovés et al. (2006) with the classified wave storms presented, only one of them corresponds to a category-V event (November 2001). This was classified in 7th position in the cyclone's intensity ranking whereas in the wave energy ranking it occupies the first place. The remaining most-intense cyclones occurred out of the buoys operation period and, in consequence, no instrumental data was available to check wave properties. However, if wave characteristics during those storms are obtained from existing hindcast wave data in the area (GuedesSoares et al., 2002), the estimated wave height and energy were lower than the ones during the November 2001 storm. In other words, a direct correspondence between cyclone's intensity and induced wave storms was not observed.

The other recorded category- $\mathrm{V}$ storm, occurring in October 2003, developed during a situation that has been classified as a Mediterranean tropical-like storm or "medicane" (Fita et al., 2007). These authors indicate that these events 

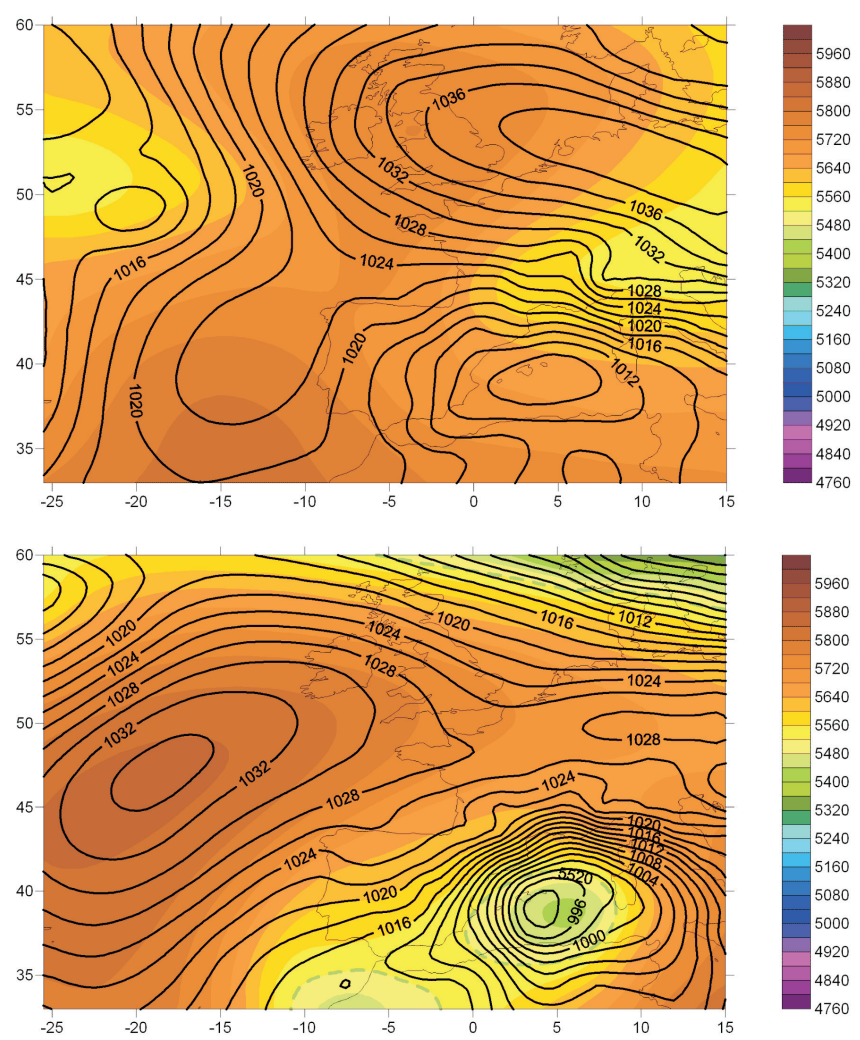

Fig. 9. SLP (lines) and Z500 (colours) during an MC situation. Top: 28/10/1997 at 12:00 UTC; bottom: 11/11/2001 at 06:00 UTC, map from ERA-Interim reanalysis done by European Centre for Medium Weather Forecast (ECMWF).

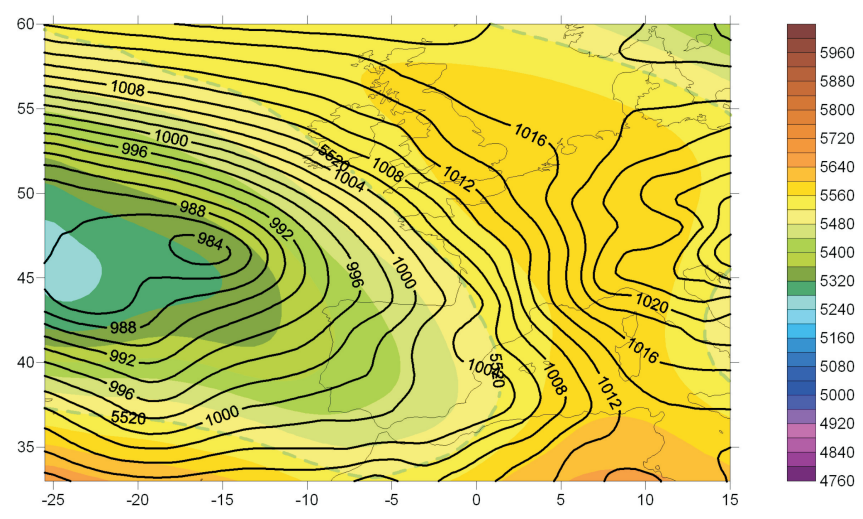

Fig. 10. SLP (lines) and Z500 (colours) during an SA situation. 22/12/2000 at 12:00 UTC from ERA-Interim reanalysis done by European Centre for Medium Weather Forecast (ECMWF).

have a potential for highly destructive effects on Mediterranean coast and, although they are relatively unusual, they have identified about 15 cases during a period of $20 \mathrm{yr}$. but only one of the 4 most intense identified on the western Mediterranean basin (Catalan-Balearic Sea) coincides with a wave storm along the Catalan coast (October 2003).

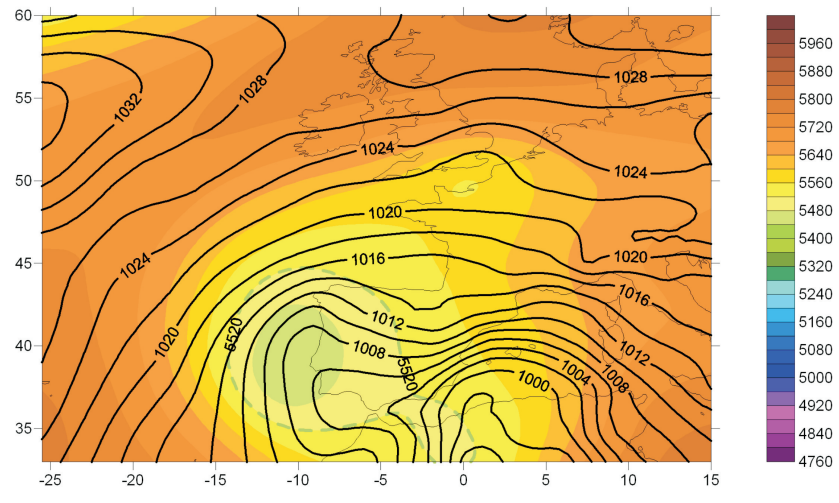

Fig. 11. SLP (lines) and Z500 (colours) during an EA situation. 07/05/2002 at 12:00 UTC from ERA-Interim reanalysis done by European Centre for Medium Weather Forecast (ECMWF).

\section{Summary}

In this work a 5-class intensity scale for wave storms in the Catalan coast (NW Mediterranean) is presented. This has been done by using the entire available wave instrumental data set which comprises 5 buoys during the period 1988/2008 covering the Catalan coast from north to south. In this sense, the obtained classification improves the former proposal of Mendoza and Jiménez (2008) by better resolving spatial and temporal variability in wave storms in the area.

The classification obtained (Table 1 and Fig. 4) reflects the increase in wave storm properties as storm category increases. Moreover, because the selected classification parameter was the energy content which implicitly contains $H_{\mathrm{s}}$ and storm duration, this variable is used to define class limits, therefore class I storms present energy contents between 24 and $250 \mathrm{~m}^{2} \mathrm{~h}$ with average values of $2.8 \mathrm{~m}$ of $H_{\mathrm{s}}$ max and $19 \mathrm{~h}$ of duration. Class II storms have energy values between 251 and $500 \mathrm{~m}^{2} \mathrm{~h}$ and average values of $3.5 \mathrm{~m}$ of $H_{\mathrm{s}}$ max and $52 \mathrm{~h}$ of duration. Class III presents limits ranging from 501 to $700 \mathrm{~m}^{2} \mathrm{~h}$ and mean values of $4.4 \mathrm{~m}$ for $H_{\mathrm{s}}$ max and $77 \mathrm{~h}$ of duration. Class IV storms can range from 701 to 1200 $\left(\mathrm{m}^{2} \mathrm{~h}\right)$ with average values of $5.1 \mathrm{~m}$ of $H_{\mathrm{s}} \max$ and $86 \mathrm{~h}$ of duration. The most intense storm class $(\mathrm{V})$ presents energy values higher than $1200 \mathrm{~m}^{2} \mathrm{~h}$ and these present $H_{\mathrm{s}}$ max mean values higher than $6 \mathrm{~m}$ and $99 \mathrm{~h}$ of duration.

Since the energy content variable is a good proxy of induced hazards, the observed increase in energy content for higher classes reflects a significant increase in the intensity of the potential hazards. Consequently, the erosion potential can range from $7 \mathrm{~m}^{3} / \mathrm{m} / \mathrm{storm}$ in a dissipative beach for a class I storm up to $100 \mathrm{~m}^{3} / \mathrm{m} / \mathrm{storm}$ in a reflective beach for a class $\mathrm{V}$ storm. In terms of flood potential, the Run up values range from $0.75 \mathrm{~m}$ in a dissipative beach in a class I storm up to $3.75 \mathrm{~m}$ in a reflective beach for a class $\mathrm{V}$ storm. Therefore, the real magnitude of the hazard is affected by the coastal geomorphology. 
The dominant synoptic situation for wave storms along the Catalan coast was MC since they exert a large influence on the weather and climate, with local winds and rain distribution being in many cases related to them (e.g. Radinovic, 1987). However, we did not find a direct correspondence on cyclone's intensity over the western Mediterranean with wave energy content. This should indicate that other storm parameters have to be considered in the analysis. At present, an analysis of the position of the low pressure centre and the track of the storm with respect to the Catalan coast is taking place. A possible consequence of this should be to use a more detailed classification for synoptic situations. Thus, the MC is a very broad class that, if used to "forecast" wave storm energy along the Catalan coast, probably has to be discriminated in a better way. A possible approach is to apply more detailed classifications such as the one developed by Campins et al. (2010), where different types of cyclones are identified.

Acknowledgements. This work has been developed in the framework of the VuCoMa research project funded by the Spanish ministry of Research and Innovation (CTM2008-05597/MAR). The first author would like to thank Conacyt. The authors wish to extend thanks to the Department of Public Works of the Generalitat de Catalunya and Puertos del Estado of the Spanish Ministry of Public Works for supplying wave data used in this study, and to the European Centre for Medium Weather Forecast (ECMWF) for synoptic maps from ERA analysis.

Edited by: J. Salat

Reviewed by: two anonymous referees

\section{References}

Bolaños, R., Sánchez-Arcilla, A., and Cateura, J.: Evaluation of two atmospheric models for wind-wave modelling in the NW Mediterranean, J. Mar. Sys., 65, 336-353, 2007.

Bunkers, M., Miller, J., and Degaetand, A.: Definition of climate regions in the Northern Plains using an objective cluster modification technique, J. Climate, 9, 130-146, 1996.

Campins, J., Genovés, A., Jansà, A., Guijarroa, J. A., and Ramis, C.: A catalogue and a classification of surface ciclones for the Western Mediterranean, Int. J. Climatol., 20, 969-984, 2000.

Campins, J., Genovés, A., Picornell, M. A., and Jansà, A.: Climatology of Mediterranean cyclones using the ERA-40 dataset, Int. J. Climatol., doi:10.1002/joc.2183, 2011.

Casas-Prat, M. and Sierra, J. P.: Trend analysis of wave storminess: wave direction and its impact on harbour agitation, Nat. Hazards Earth Syst. Sci., 10, 2327-2340, doi:10.5194/nhess-102327-2010, 2010.

Cateura, J., Sánchez-Arcilla, A., Bolaños-Sánchez, R., and Sairouni, A.: Atmospheric conditions during severe wave storms in the North-Western Mediterranean. Generation, evolution, decay and implications, 37th CIESM Congress, Barcelona, Spain, 90 pp., 2004.

CIIRC: Estat de la Zona Costera a Catalunya, International Centre for Coastal resources Research, Generalitat de Catalunya, Barcelona, 2009.
Dolan, R. and Davis, R.: An intensity scale for Atlantic coast northeast storms, J. Coast. Res., 8(4), 840-853, 1992.

Fita, L., Romero, R., Luque, A., Emanuel, K., and Ramis, C.: Analysis of the environments of seven Mediterranean tropicallike storms using an axisymmetric, nonhydrostatic, cloud resolving model, Nat. Hazards Earth Syst. Sci., 7, 41-56, doi:10.5194/nhess-7-41-2007, 2007.

García, M. A., Sánchez-Arcilla, A., Sierra, J. P., Sospedra, J., and Gómez, J.: Wind waves of the Ebro delta, NW Mediterranean, J. Mar. Syst., 4(2/3), 235-262, 1993.

Genovés, A., Campins, J., and Jansà, A.: Intense storms in the Mediterranean: a first description from the ERA-40 perspective, Adv. Geosci., 7, 163-168, doi:10.5194/adgeo-7-163-2006, 2006.

Guedes Soares, C.: Hindcast of Dynamic Processes of the Ocean and Coastal Areas of Europe, Coast. Eng., 55, 825-826, 2008.

Guedes-Soares, C., Weisse, R., Carretero, J. C., and Alvarez, E.: A 40 years hindcast of wind, sea level and waves in European waters, Proc. 21st Int. Conf. on Offshore Mechanics and Arctic Engineering, ASME, Paper OMAE2002-28604, 2002.

Jiménez, J. A., Sánchez-Arcilla, A., Valdemoro, H. I., Gracia, V., and Nieto, F.: Processes Reshaping the Ebro Delta, Mar. Geol., 144, 59-79, 1997.

Jiménez, J. A., Valdemoro, H. I., and Sánchez-Arcilla, A.: Bayed beaches behaviour under storms. Effects of storm direction, intensity, duration and water level on beach erosion, Proceedings of the Int. Conf. Coastal Sediments 2003. CD-ROM Published by World Scientific Publishing Corp. \& East Meets West Productions, Corpus Christi, Texas, 2003.

Lionello, P., Bhend, J., Buzzi, A., Della-Marta, P. M., Krichak, S. O., Jansà, A., Maheras, P., Sanna, A., Trigo, I. F., and Trigo, R.: Cyclones in the Mediterranean Region: Climatology and Effects on the Environment, in: Developments in Earth and Environmental Sciences, IV: Mediterranean Climate Variability, edited by: Lionello, P., Malanotte-Rizzoli, P., Boscolo, R., 325-372, 2006.

Mendoza, E. T.: Coastal vulnerability to storms in the Catalan coast, $\mathrm{PhD}$ thesis, Universitat Politecnica de Catalunya, 2008.

Mendoza, E. T. and Jiménez, J. A.: Storm-Induced Beach Erosion Potential on the Catalonian Coast, J. Coast. Res., SI ,48, 81-88, 2006.

Mendoza, E. T. and Jimenez, J. A.: Clasificación de tormentas costeras para el litoral Catalán (Mediterráneo NO), Ing. Hidraul Mex., XXIII, 2, 21-32, 2008.

Mendoza, E. T. and Jiménez, J. A.: Regional geomorphic vulnerability analysis to storms for Catalan beaches, P. I. Civil Eng-Mar. En., 162(3), 127-135, 2009.

Morton, R. R. and Sallenger A. H.: Morphological Impacts of Extreme Storms on Sandy Beaches and Barriers, J. Coast. Res, 19(3), 560-573, 2003.

Ojeda, E. and Gullién, J.: Shoreline dynamics and beach rotation of artificial embayed beaches, Mar. Geol., 253, 51-62, 2008.

PAP/RAC.ICZM: Protocol in the Mediterranean, available at: http://www.pap-thecoastcentre.org/razno/ PROTOCOLENGFINALFORMAT.pdf (last access: June 2011), 2007.

Ponce de León, S. and Guedes Soares, C. Sensitivity of a Wave Model Predictions to Wind Fields in the Western Mediterranean Sea, Coas. Eng., 55, 920-929, 2008.

Radinovic, D.: Mediterranean Cyclones and Their Influence on the 
Weather And Climate, PSMP Report Series number 24, WMO, 1987.

Ratsimandresy, A. W., Sotillo, M. G., Carretero Albiach, J. C., Álvarez Fanjul, E., and Hajji, H.: A 44-year high-resolution ocean and atmospheric hindcast for the Mediterranean Basin developed within the HIPOCAS Project, Coast. Eng., 55, 827-842, 2008.

Saffir, H.: Design and construction requirements for hurricane resistant construction, Am. Soc. Civil Eng., ASCE Preprint No. 2830, American Society of Civil Engineers, New York, 20 pp., 1977.
Sardá, R., Avila, C., and Mora, J.: A methodological approach to be used in integrated coastal zone management process: the case of the Catalan Coast (Catalonia, Spain), Estuar. Coast. Shelf Sci., 62, 427-439, 2005.

Simpson, R. A.: Proposed scale for ranking hurricanes by intensity, Minutes of the Eighth NOAA, NWS Hurricane Conference, Miami, 1971.

Stockdon, H. F., Holman, R. A., Howd, P. A., and Sallenger, A. H.: Empirical parameterization of setup, swash, and runup, Coast. Eng., 53(7), 573-588, 2006.

Trigo, I. F., Bigg, G. R., and Davis, T. D.: Climatology of cyclogenesis mechanisms in the Mediterranean, Mon. Weather Rev., 130, 549-569, 2002. 